\title{
ANALYSIS OF SWITCHED RELUCTANCE MOTOR BEHAVIOR UNDER ELECTRICAL FAULT CONDITIONS
}

This paper deals with analysis of Switched Reluctance Motor (SRM) behavior under fault conditions. The static parameters of the healthy SRM and SRM with defined faults of phases are investigated by Finite Element Method (FEM). These static parameters are used in dynamic simulation of the SRM. Transients are simulated for the healthy motor and for the motor under fault conditions. Results of the simulations are compared with experimental measurements.

Keywords: Switched reluctance motor, fault operation, parameter analysis

\section{Introduction}

The Switched Reluctance Motor (SRM) is one of the simplest and robust electrical machines. Torque of SRM is produced by tendency of rotor to move to a position where the inductance of the excited winding is maximized [1].

The SRM construction is very simple. It is a double salient electrical machine which has only stator winding and rotor is passive. Each phase comprises two coils wound on opposite stator poles and connected in series or parallel [2]-[4]. The cross-section area of the three phase 6/4 SRM is shown in Fig. 1a. In Fig. 1b, there is a photo of the investigated SRM.

In many applications, the drive reliability is a very important task from the point of view of fault operation. There are several types of fault states which could occur during the SRM operation. Mechanical, magnetic or electrical faults of the motor could occur. This paper is focused on electrical faults of SRM.

The electrical faults could be: short circuit in one coil of a phase (all turns or some turns), a whole coil is bridged by a short circuit, the whole phase is short circuited, open circuit in one coil of a phase, a short circuit between two different phases, a short circuit from one winding to ground [5], [6].

In [7] electrical faults detection and special fault tolerant design of the 12/14 SRM are studied, where the winding scheme is a six phased duplex type (each phase is doubled). When a fault of one channel occurs the second channel still contributes to the torque generation. Some simulations of the winding faults are presented.
In [8] a fault-tolerant SRM drive with adaptive fuzzy logic controller providing smooth torque with minimum ripple under normal and fault conditions is described.

Some fault states are analyzed in [9]. In this paper the static and dynamic faults of real 6/4 SRM are investigated. The static analysis is carried out by means of FEM and the phase inductance, flux linkage and air gap torque are analyzed under normal and fault conditions. These static parameters are used in the dynamic simulation of the SRM and transients are calculated also for health and fault operated motor. The simulated results are compared with experimental ones.

The nameplate of the investigated SRM is shown in Table 1.

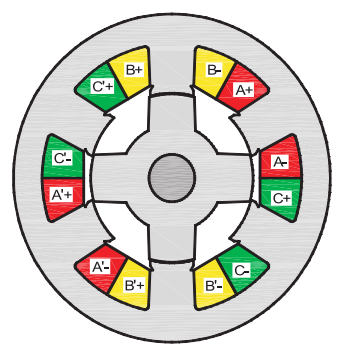

a)

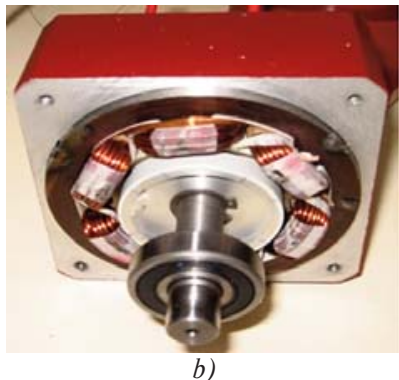

b)
Fig. 1 The investigated SRM, a) cross-section area, a photo of open motor

The nameplate of the investigated 6/4 SRM

Table 1.

\begin{tabular}{|c|c|c|}
\hline Rated voltage & Rated current & Rated speed \\
\hline $3 \times 10 \mathrm{~V}$ & $28.5 \mathrm{~A}$ & $5000 \mathrm{rpm}$ \\
\hline
\end{tabular}

\footnotetext{
* Peter Dubravkaa ${ }^{1}$, Pavol Rafajdus ${ }^{1}$, Pavol Makys ${ }^{1}$, Valeria Hrabovcova ${ }^{1}$, Lorand Szabo ${ }^{2}$

${ }^{1}$ Department of Power Electrical Systems, Faculty of Electrical Engineering, University of Zilina, Slovakia, E-mail: pavol.rafajdus@kves.uniza.sk

${ }^{2}$ Department of Electrical Machines and Drives, Technical University of Cluj-Napoca, Cluj-Napoca, Romania
} 


\section{FEM analysis of the SRM static parameters}

There are several methods how to analyze the static parameters of the SRM [10] and [11]. Very useful and accurate is Finite Element Analysis (FEA) which is used in this paper. For the FE magnetostatic analysis the following input data are needed: geometrical dimensions of the machine, current density of one phase, material constants (winding conductivity and relative permeability, B-H curve of SRM ferromagnetic circuit material) and boundary conditions. The parametric model of SRM was created in LUA script in the FEMM 4.2 software for more convenient calculation with lower time consumption. The LUA script also enables the SRM model configurations (changes of the machine geometry or other parameters) during the execution of the script.

The static characteristics of the SRM were analyzed by means of FEM under four different winding fault conditions. Namely $0 \%$, $20 \%, 50 \%, 70 \%$ of winding turns are in the short circuit that corresponds to $25,20,13,8$ winding turns respectively.

The accuracy of the result depends on the size of FEM mesh and accuracy of the input parameters. In this model, 11578 nodes were used. The calculation was carried out for each individual rotor position and current under static condition. The rotor position $\Theta$ was moved from unaligned $\Theta_{u}$ to aligned position $\Theta_{a}$ with step of $1^{\circ}$ and in each position the current was changed within its working

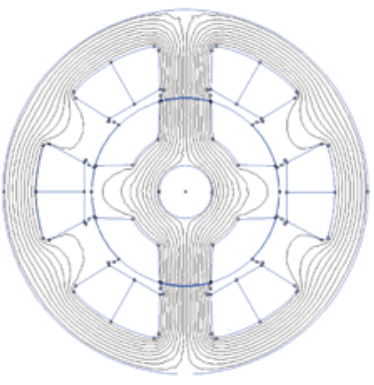

a)

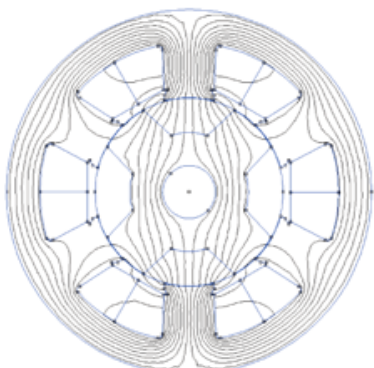

b)
Fig. 2 FEM analysis of the SRM, flux lines of the healthy SRM, a) aligned rotor position, b) unaligned rotor position

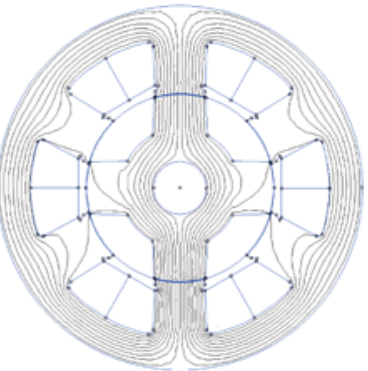

a)

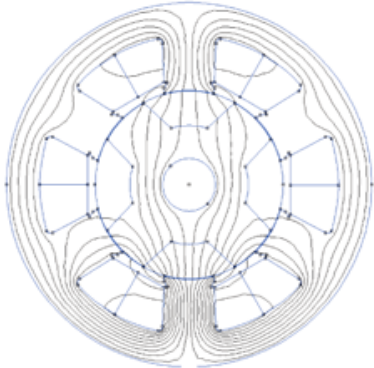

b)
Fig. 3 FEM analysis of the SRM, flux lines of the SRM, where $50 \%$ of coil "B" turns are in short circuit; a) aligned rotor position, b) unaligned rotor position. range from 1 to 28 A. In Fig. 2 the distribution of magnetic flux lines of healthy SRM for aligned and unaligned position can be seen. For comparison, in Fig. 3, there is a distribution of magnetic flux lines of fault SRM for aligned and unaligned position if 50\% of coil "B" turns are in short circuit.

Magnetic flux linkage calculation

The first parameter to be analyzed is the flux linkage versus phase current for different rotor position $\psi=f(I, \Theta)$. The area bounded by maximal phase current and by both $\psi-I$ curves for aligned and unaligned positions is equal to mechanical energy, which is converted to electromagnetic force [1]. In Fig. 4 the flux linkage for various rotor positions and currents can be seen. In Fig. 5 the curves obtained by means of FEM for different rotor positions can be seen, if the phase current is kept constant $13 \mathrm{Amps}\left(0^{\circ}\right.$ is equal to unaligned rotor position and $45^{\circ}$ is equal to aligned rotor position). The investigated phase is B. As it can be seen from this Fig. 5, the flux linkage is decreased with increasing phase turns in short circuit.

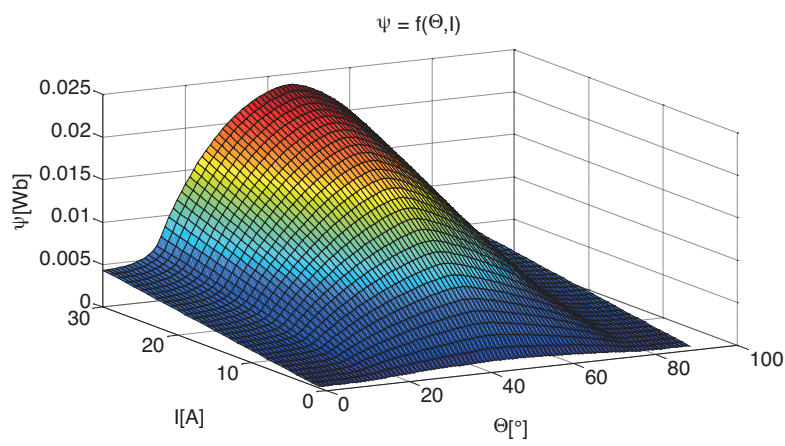

Fig. 4 FEM analysis of the SRM, flux linkage for various rotor positions and currents

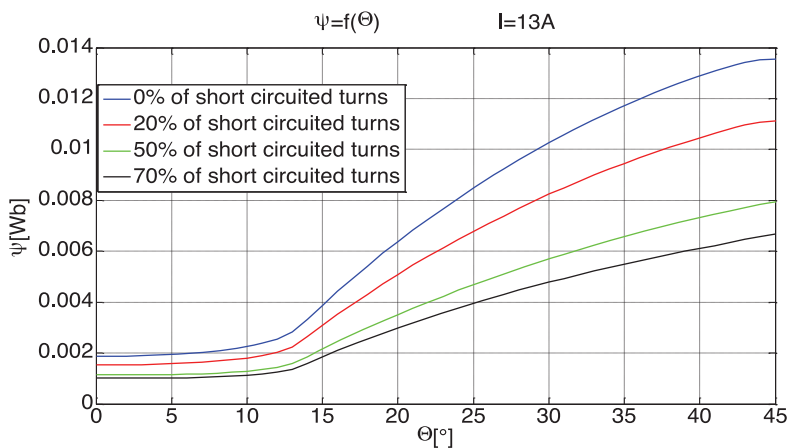

Fig. 5 FEM analysis of the SRM, flux linkage versus rotor position for constant phase current $13 \mathrm{~A}$

\section{A. Phase inductance calculation}

The phase inductance $L=f(I, \Theta)$ versus rotor position for full current range is a static parameter which is needed in SRM mathematical model for dynamic simulations. The analysis was made for the whole working range. The phase inductance profiles are 
shown in Fig. 6. The results are obtained by means of FEM for SRM in accordance with the following equation:

$$
L=\frac{\int A \cdot J d V}{I^{2}} .
$$

where $A$ is magnetic vector potential, $J$ is current density, $V$ is volume and $I$ is phase current.

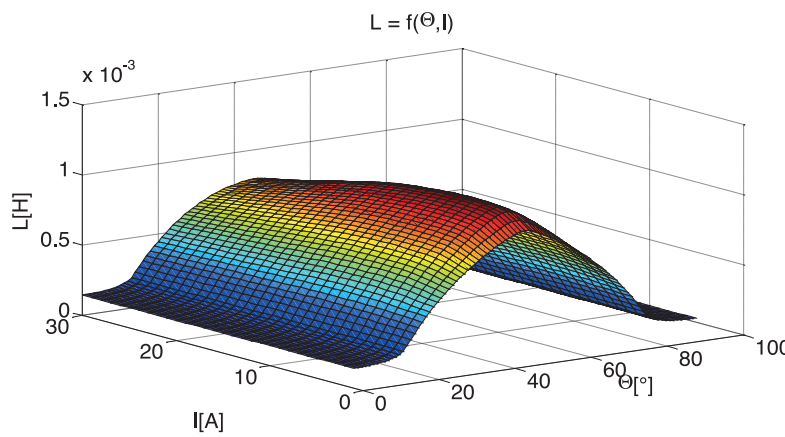

Fig. 6 FEM analysis of the SRM, the phase inductance for various rotor positions and various phase currents

The phase inductance for various rotor position and curren 13A under different winding faults can be seen in Fig. 7. The phase inductance is decreased with increasing phase turns in short circuit.

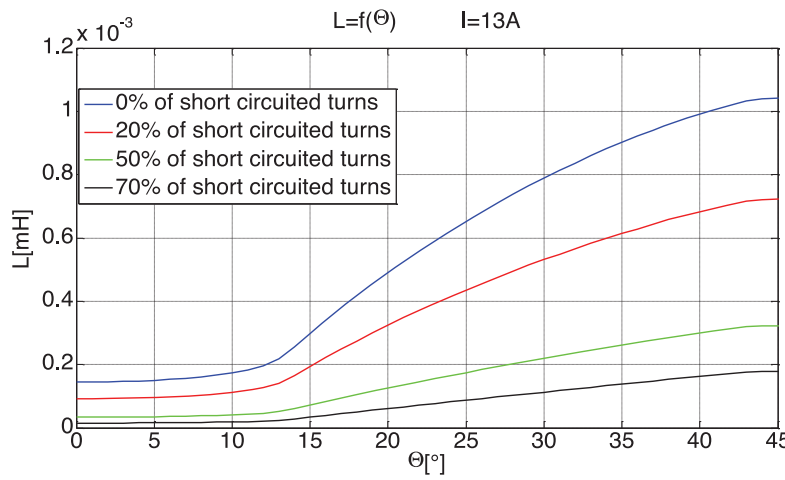

Fig. 7 FEM analysis of the SRM, phase inductance versus rotor position for constant phase current $13 \mathrm{~A}$

\section{B. Electromagnetic torque calculation}

The electromagnetic torque was also calculated by means of FEM. The static torque characteristics were obtained for the whole working range. Maxwell's stress tensor prescribes the torque per unit area produced by the magnetic field in the air gap of the motor. The differential torque produced is:

$$
d T=\frac{1}{2}(H(B \cdot n)+B(H \cdot n)-(H-B) n) .
$$

where $n$ denotes the direction normal to the surface at the point of interest, $B$ is flux density and $H$ is intensity of magnetic field.
The static electromagnetic torque of phase $\mathrm{B}$ in the air gap $T_{\delta}$ for various rotor positions and various phase currents is shown in Fig. 8.

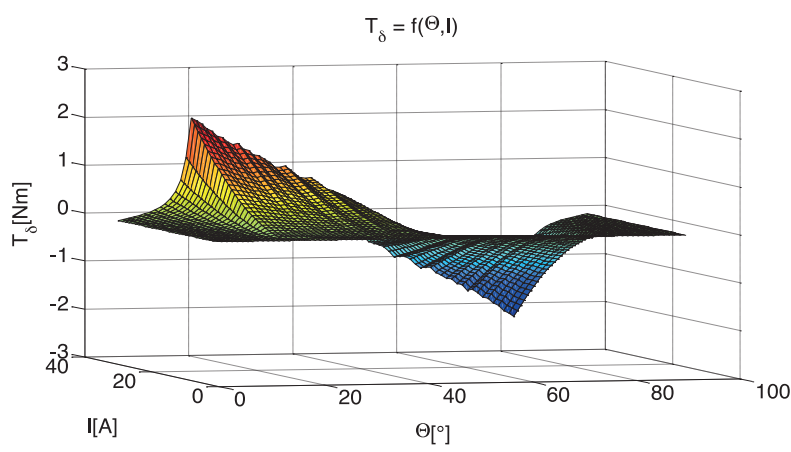

Fig. 8 FEM analysis of the SRM, the static electromagnetic torque of phase in the air gap $T_{\delta}$ for various rotor positions and various phase currents

The static electromagnetic torque of phase $\mathrm{B}$ in the air gap $T_{\delta}$ for various rotor positions and constant phase current $13 \mathrm{~A}$ under different winding faults is shown in Fig. 9. The static electromagnetic torque in the air gap is decreased with increasing phase turns in short circuit.

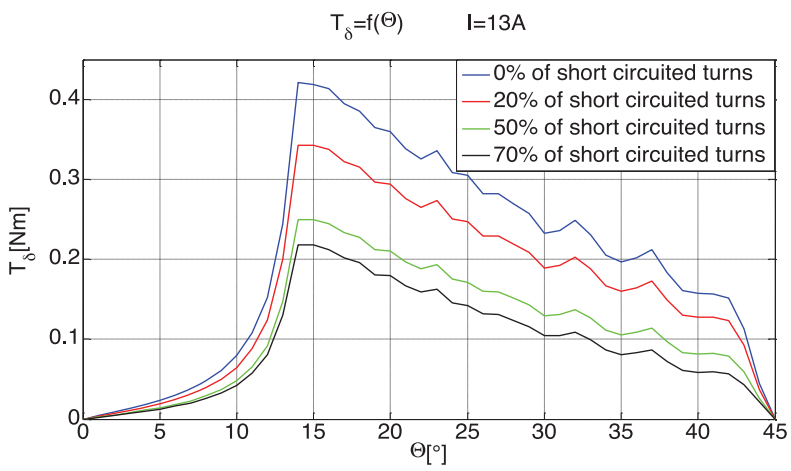

Fig. 9 FEM analysis of the SRM, the static electromagnetic torque of phase $B$ in the air gap $T_{\delta}$ for various rotor positions and constant phase current $13 \mathrm{~A}$

\section{Mathematical model of SRM}

As it is known the mathematical model of the SRM needs input static parameters to be able to solve transients. The static parameters: flux linkage, phase inductance, developed electromagnetic torque of SRM are obtained by means of FEM and they are used in this mathematical model to calculate following values: phase current, speed, voltage and dynamic torque of the SRM during normal operation and also during fault operation.

As it is known the electromagnetic torque of SRM can be calculated from: 


$$
T_{e}=\frac{\partial \int_{0}^{i} \Psi d i}{\partial \Theta}
$$

where $i$ is phase current, $\Psi$ is phase flux linkage and $\Theta$ is rotor position. To obtain dynamic total torque of SRM, the simulation of its mathematical model is needed.

The mathematical model of SRM consists of the following equations, if:

- leakage inductances between phases are neglected,

- iron losses are neglected,

- phase inductance depends on phase current and rotor position.

The voltage equation of one SRM phase is given as:

$$
v=R i+\frac{d \psi}{d t} \text {. }
$$

where $R$ is phase resistance, $i$ is phase current and $\psi$ is flux linkage. The flux linkage depends on both parameters: phase current and rotor position $(\psi=f(i, \Theta))$. Then

$$
\frac{d \psi}{d t}=\frac{\partial \psi}{\partial i} \frac{d i}{d t}+\frac{\partial \psi}{\partial \Theta} \frac{d \Theta}{d t} .
$$

The phase current is calculated from combination of (4) and (5) as:

$$
\frac{d i}{d t}=\frac{v-\left(R+\frac{d L(i, \Theta)}{d \Theta} \omega\right) i}{L(i, \Theta)} .
$$

The real angular speed is calculated from equation:

$$
\frac{d \omega}{d t}=\frac{1}{J}\left(\sum_{j=1}^{m} T_{j}(\Theta, i)-T_{\text {load }}\right) .
$$

where $J$ is the moment of inertia and $T_{\text {load }}$ is load torque.

The SRM is controlled on the base of rotor position $\Theta$, therefore it is as follows

$$
\Theta=\int \omega d t .
$$

\section{Dynamic simulation of SRM}

Simulation model was created under Matlab. The model of a single phase is shown in Fig. 10.

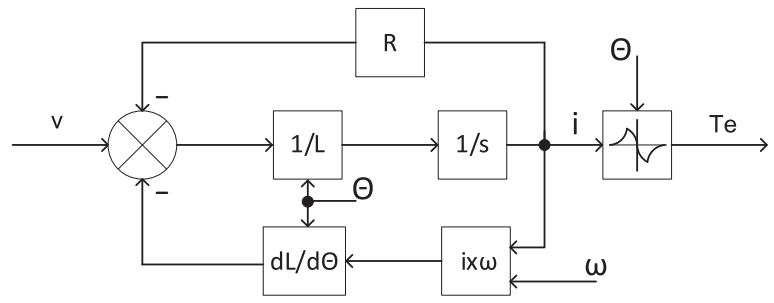

Fig. 10 Dynamic model of the SRM, one phase is shown only

To control rotor speed, PI controller is used. The PI controller is implemented in the discrete version, therefore, the control signal $u(k)$ is given as:

$$
u(k)=K_{p}\left[e(k)+\frac{T}{T_{i}} \sum_{i=0}^{k-1} e(i)\right] .
$$

where $k$ is a discrete time instant and $T$ is sampling time.

The hysteresis controller is used to control phase current. The phase voltage in (4) is given by DC voltage source, which supplied the converter of SRM. By this control the voltage can have three values, if the voltage drops on the transistors and diodes are neglected:

a) $v=+V_{s}$, if the phase current $i$ is lower than low limit of the hysteresis region,

b) $v=0$, if the phase current is higher than high limit of the hysteresis region,

c) $v=-V_{s}$, if the phase current is switched off.

The control structure which is used in order to simulate SRM's transient is shown in Fig. 11. The coefficients of PI controller are tuned by a trial and error method.

The SRM investigation was made for different speeds.

In dynamic simulation, the start up of the SRM was simulated for three required speeds. In the first case the start up of a healthy

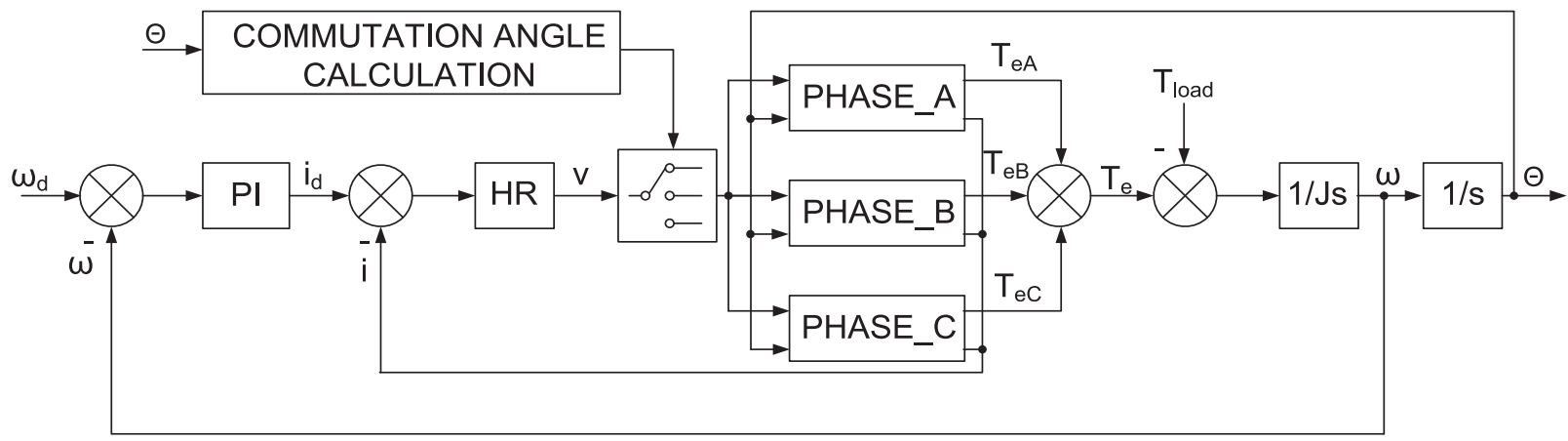

Fig. 11 The block diagram of SRM speed control with PI controller 
motor was simulated up to time 0.11 (see Fig. 12) and then, the phase A fallout occurred. It means that the phase A is not active. The load torque was kept constant $0.1 \mathrm{Nm}$ and required speed was $180 \mathrm{rpm}$. After the phase fallout occurs, the speed decreases under the required speed value and speed ripple occurred about $17 \%$ from the required speed. Currents in three phases up to time 0.1 can be seen in Fig. 13. After this time the phase A fallout occurred (the phase current is $0 \mathrm{~A}$ ). The phase current of phase $\mathrm{B}$ is higher than in phase $\mathrm{C}$, which can be caused by the switch ON and switch OFF angles setup.

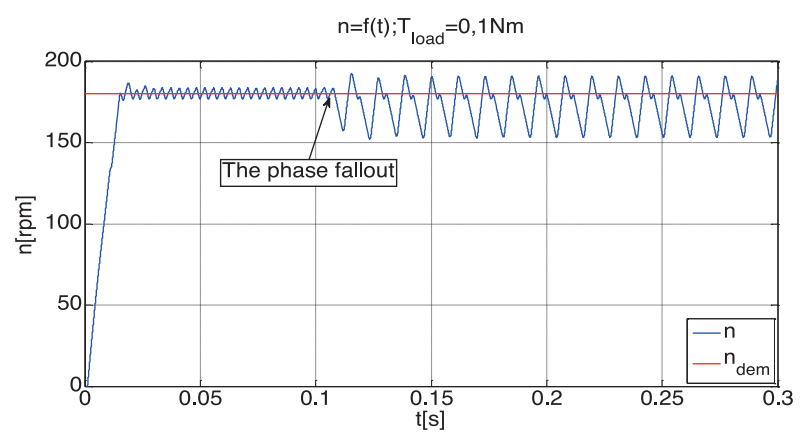

Fig. 12 Dynamic simulation of SRM speed with $n_{\text {dem }}=180 \mathrm{rpm}$, the start up of healthy motor and the phase A fallout occurred

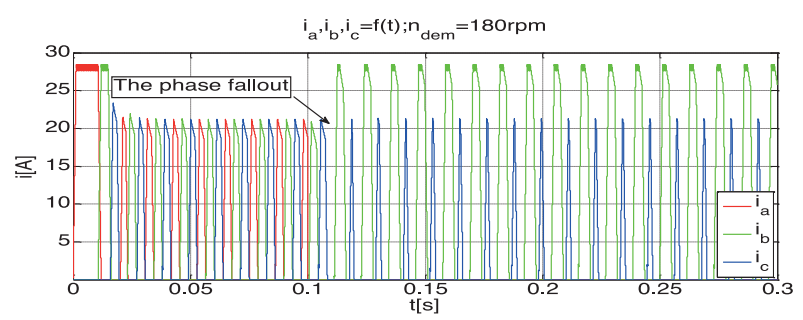

Fig. 13 Dynamic simulation of SRM currents with $n_{\text {dem }}=180 \mathrm{rpm}$, the start up of healthy motor and the phase A fallout occurred

In Fig. 14, there is start up of the motor up to $300 \mathrm{rpm}$ with three phases and in time $t=0.1 \mathrm{~s}$ A phase fault occurred. After the phase fallout occurs, the speed decreases under the required speed value and speed ripple occurred about $5 \%$ from the required speed. Currents in three phases up to $0.1 \mathrm{~s}$ can be seen in Fig. 15 . After this time the phase A fallout occurred (the phase current is $0 \mathrm{~A})$. The phase current of phase $\mathrm{B}$ is higher than in phase $\mathrm{C}$, which can be caused by the switch ON and switch OFF angles setup.

In Fig. 16, there is start up of the motor up to $1000 \mathrm{rpm}$ with three phases and in time $t=0.12 \mathrm{~s}$ one phase fault occurred. After the phase fallout occurs, the speed decreases under the required speed value and speed ripple occurred about $2 \%$ from the required speed. Currents in three phases can be seen in Fig. 17.

As it can be seen from these analyses, when the speed increases, the speed ripple decreases. It is given by the inertia of the system.

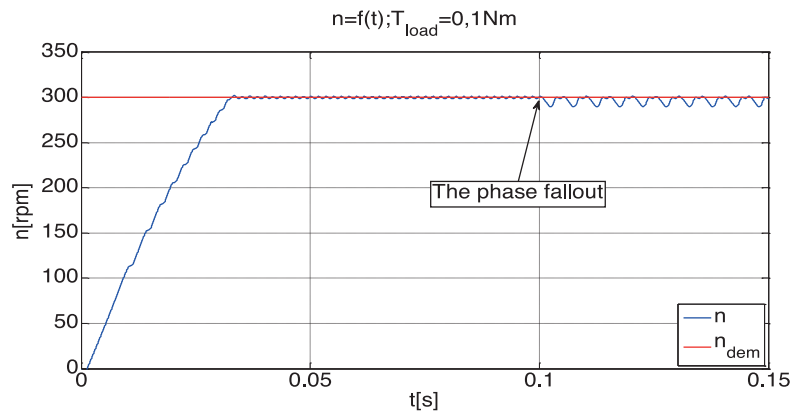

Fig. 14 Dynamic simulation of SRM speed with $n_{\text {dem }}=300 \mathrm{rpm}$, the start up of healthy motor and the phase A fallout occurred

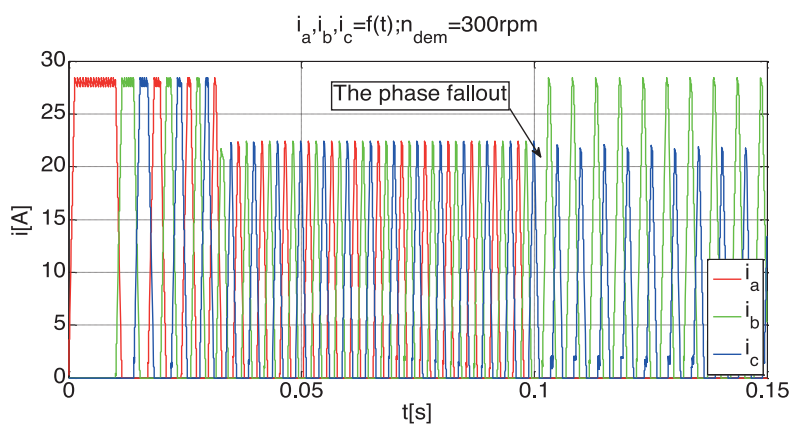

Fig. 15 Dynamic simulation of SRM currents with $n_{\text {dem }}=300 \mathrm{rpm}$, the start up of healthy motor and the phase A fallout occurred

This was simulated for torque $0.1 \mathrm{Nm}$ and speed up to $1000 \mathrm{rpm}$. In the future it will be analyzed for rated speed and rated torque.

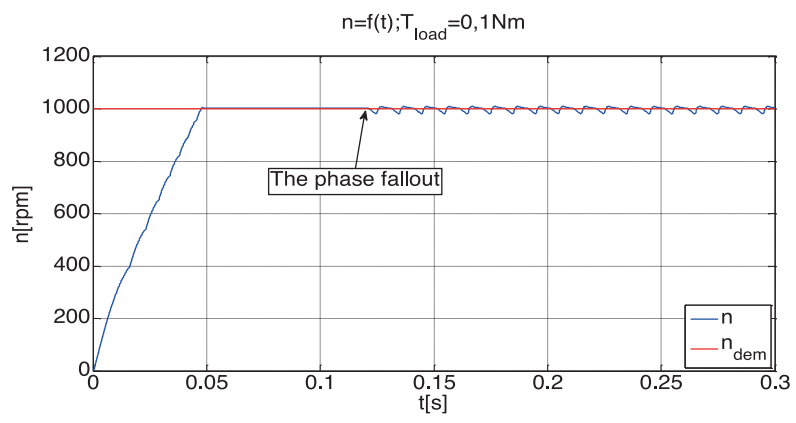

Fig. 16 Dynamic simulation of SRM speed with $n_{\text {dem }}=1000 \mathrm{rpm}$, the start up of healthy motor and the phase A fallout occurred

\section{Experimental results}

To verify the simulated dynamic result an experimental test rig with SRM coupled with BLDC load was carried out. The test rig is shown in Fig. 18. The control board equipped with a Digital Signal Controller by Freescale was used [12] and [13]. The control board is connected with low power and a low voltage converter which supplies the SRM. The control loop consists of a speed 


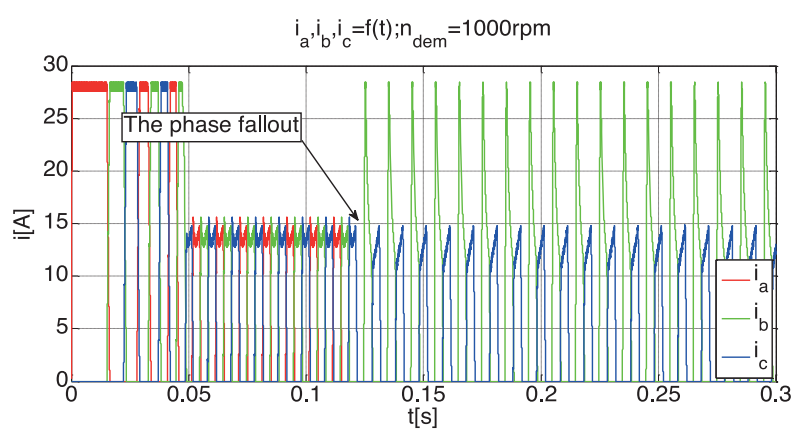

Fig. 17 Dynamic simulation of SRM currents with $n_{\text {dem }}=1000 \mathrm{rpm}$, the start up of healthy motor and the phase A fallout occurred

loop with PI controller and a slave current loop made by hysteresis current controllers.

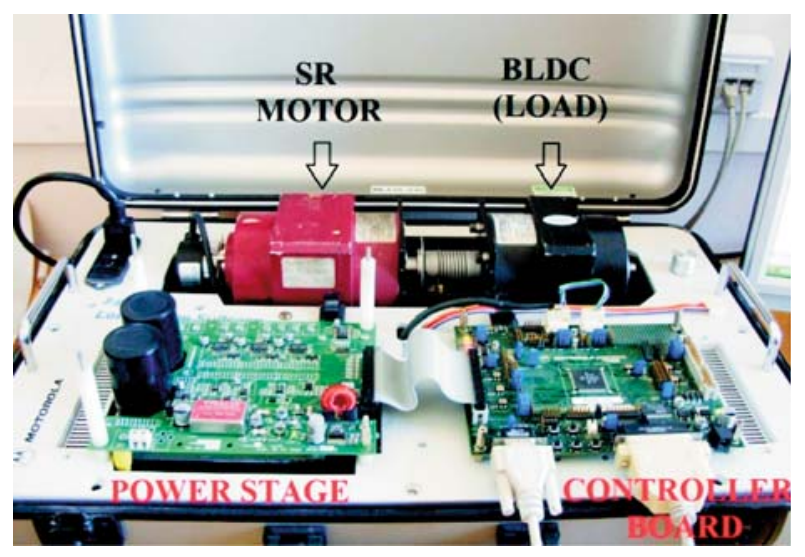

Fig. 18 Experimental test rig equipped with SRM and BLDC load

The measured speed start up of the healthy SRM is shown in Fig. 19. The load torque was kept constant $0.1 \mathrm{Nm}$.

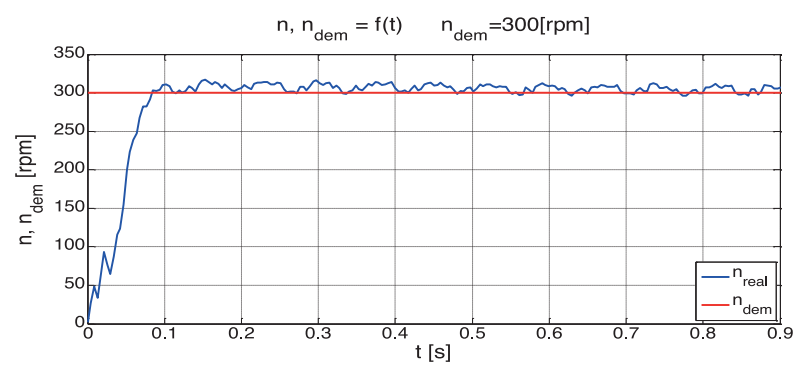

Fig. 19 The measured speed start up of the healthy SRM.

The measured phase currents for start up and steady state of the healthy SRM are presented in Fig. 20.

The measured start up of the healthy SRM where the required speed is $1000 \mathrm{rpm}$ is shown in Fig. 21.

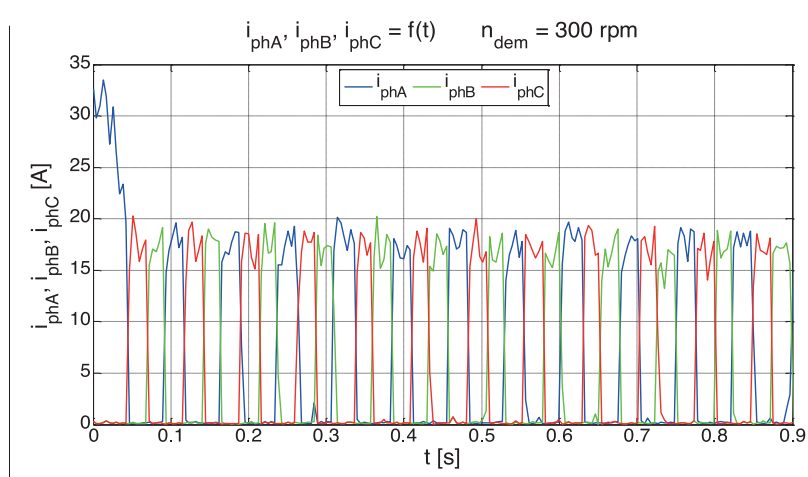

Fig. 20 The measured phase currents for start up of the healthy SRM

The measured phase currents for start up and steady state of the healthy SRM for the required speed $1000 \mathrm{rpm}$ are shown in Fig. 22.

The start up of the healthy SRM and fallout of one phase in time $1.9 \mathrm{~s}$, for the required speed $180 \mathrm{rpm}$ are shown in Fig. 23. It means that one phase was un-plugged from the motor.

The measured phase currents for start up of the healthy SRM for the required speed $180 \mathrm{rpm}$ and in time $1.9 \mathrm{~s}$ and fallout of one phase are shown in Fig. 24.

The speed and currents are filtered with an exponential filter to remove the noise.

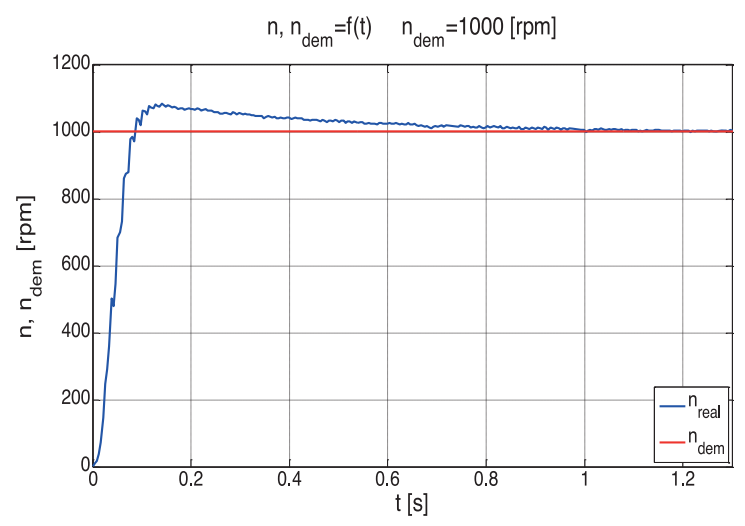

Fig. 21 The measured speed start up of the healthy SRM at $0.1 \mathrm{Nm}$

\section{Conclusion}

In this paper the static and dynamic analyses of the SRM fault operations are presented. The SRM static parameters were calculated by means of FEM for a healthy and short circuit phase. The mathematical model of the SRM was derived and used for dynamic simulation. The dynamic health and the phase fallout of the motor are analyzed by simulations and the results are compared with the measured ones. There are some differences caused by lower accuracy of the switch $\mathrm{ON}$ and switch OFF angles setup in simulation 


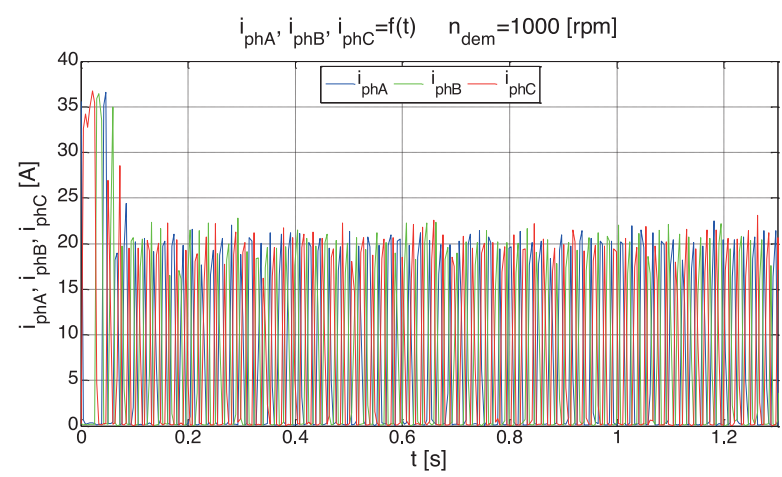

Fig. 22 The measured phase currents for start up of the healthy SRM

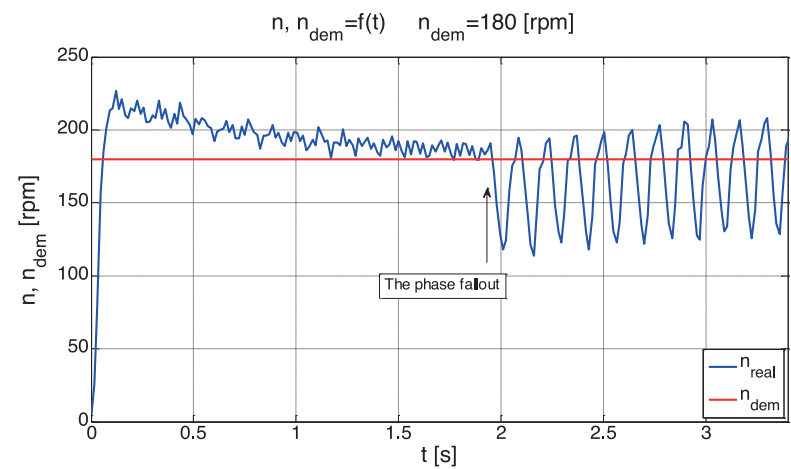

Fig. 23 The start up of the healthy SRM and fallout of one phase

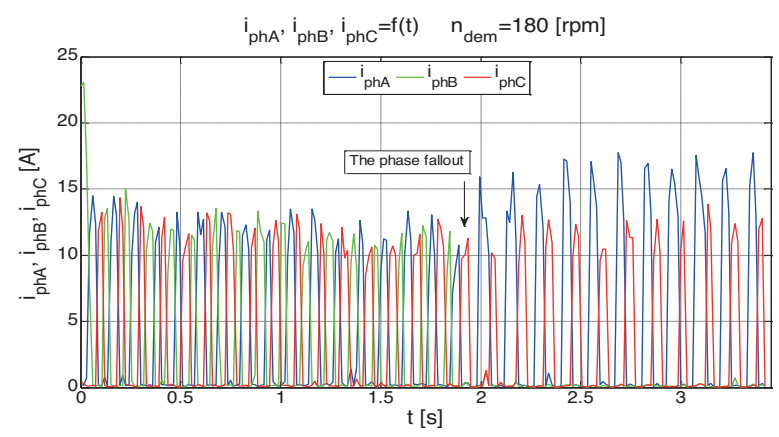

Fig. 24 The measured phase currents for start up of the healthy SRM and fallout of one phase

and in real SRM drive. This will be solved in the future also with higher speed and torque and for some other faults in the SRM.

On the base of this analysis verification, the simulation model can be used for other fault operation investigation and some recommendations can be done.

\section{Acknowledgment}

This work was supported by the Slovak Research and Development Agency under the Contract No. SK-RO-0016-10 and VEGA No. 1/0940/13 and R\&D operational program Centre of excellence of power electronics systems and materials for their components II. No. OPVaV-2009/ 2.1/02-SORO, ITMS 26220120046 funded by European regional development fund (ERDF). Authors also like to thank the Freescale Semiconductors in Czech Republic for their support.

\section{References}

[1] MILLER, T. J. E.: Electronic Control of Switched Reluctance Machines. Oxford (U.K.) : Newnes, 2001.

[2] MILLER, T. J. E.: Switched Reluctance Motors and their Control, Magna Physics, 1992.

[3] PYRHONEN, J., JOKINEN, T., HRABOVCOVA, V.: Design of Rotating Electrical Machines, John Wiley \& Sons, 2008.

[4] KRISHNAN, R.: Switched Reluctance Motor Drives - Modeling, Simulation, Analysis, Design, and Applications, CRC Press LLC, FLA, USA, 2000.

[5] SCHINNERL, B., GERLING, D.: Analysis of Winding Failure of Switched Reluctance Motors, Proc. of the IEEE Intern. Electric Machines and Drives Conference (IEMDC '09), Miami, pp. 738-743.

[6] TEREC, R., BENTIA, I., RUBA, M., SZABO, L., RAFAJDUS, P.: On the Usefulness of Numeric Field Computations in the Study of the Switched Reluctance Motor's Winding Faults, ISCIII $2011-5^{\text {th }}$ Intern. Symposium on Computational Intelligence and Intelligent Informatics, art. no. 6069753, pp. 117-120.

[7] SZABO, L., RUBA, M.: On Fault Tolerance Increase of Switched Reluctance Machines, EUROCON 2009, pp. 18-23, May 2009

[8] MIR, S., ISLAM, M.S., SEBASTIAN, T., HUSAIN, I.: Fault-Tolerant Switched Reluctance Motor Drive Using Adaptive Fuzzy Logic Controller, Power Electronics, IEEE Transactions on, March 2004

[9] KACENKA, V., RAFAJDUS, P., MAKYS, P.,VAVRUS, V., SZABO, L.: Static and Dynamic Fault Analysis of Switched Reluctance Motor, Intern. conference ELEKTRO 2012, Rajecke Teplice, 2012, Slovakia, IEEE Xplore

[10] RAFAJDUS, P., HRABOVCOVA, V., HUDAK, P.: Investigation of Losses and Efficiency in Switched Reluctance Motor, EPE-PEMC 2006, Portoroz, Slovenia

[11] RAFAJdUS, P., SEKERAK, P., KALAMEN, L., HRABOVCOVA, V.; CHEN, H.: Static and Dynamic Analysis of Linear Switched Reluctance Machine, Communications - Scientific Letters of the University of Zilina, 4/2011

[12] DIRENZO, M. T.: Switched Reluctance Motor Control - Basic Operation and Example Using the TMS320F240, Application Report, Texas Instruments, 2000

[13] VISINKA, R., BALAZOVIC, P.: 3-Phase Switched Reluctance Motor Control with Encoder Using DSP56F80x, MOTOROLA Inc., 2002. 